\title{
Depo Çalışanlarının Bilişim Sistemlerine Yaklaşımları Üzerine Bir Araştırma $^{1}$
}

\author{
Kübra SARGIN² ve Yücel ÖZTÜRKOĞLU ${ }^{3}$
}

\section{$\ddot{\mathrm{O} z}$}

Depolama, lojistik süreçleri içerisinde hem üretici hem de tüketici açısından oldukça önemli bir yere sahiptir. Etkin planlanmış depolama süreçlerinin, iş akışına ve maliyetler üzerine etkisi göz ardı edilemez. Depoların, bu avantajlardan faydalanabilmesi için, bilişim sistemleri ile entegre olmaları, verimlilikleri için oldukça önemlidir. Bu çalışmada, etkin depo yönetimi ve planlaması için bilişim sistemlerinin etkisi incelenmiştir. Konu ile ilgili literatür araştırması yapılarak, dört farklı hipotez oluşturulmuştur. Anket uygulaması sonucunda depo içinde farklı görevlerde yer alan 156 kişi tarafından elde edilen veriler kapsamında bilişim sistemlerinin depolama süreçlerinin basitleşmesinde, standartlaşmasında, etkin ve verimli sonuçlar doğurmasında etkili olduğu sonucuna varılmıştır.

Anabtar Kelimeler: Depo, Bilişim sistemleri, Depo yönetim sistemleri, Anket, Lojistik

\section{A Study on the Approach of Warehouse Employees to Information Systems}

\section{Abstract}

Warehousing has a very important place both in terms of producer and consumer in logistics processes. The effect of effective planned storage processes on workflow and costs cannot be ignored. In order to benefit from these advantages, warehouses must be integrated with the information systems, which is very important for their efficiency. In this study, the effect of information systems on effective warehouse management and planning is examined. Four different hypotheses were created by conducting a literature search on the subject. As a result of the questionnaire application, it was concluded that the information systems obtained by 156 persons who work in warehouse with a different position, were effective in simplifying, standardizing, and producing effective and efficient results of storage processes.

Key Words: Warehouse, Information systems, Warehouse management systems, Survey, Logistics

\section{Atıf İçin / Please Cite As:}

Sargın, K. ve Öztürkoğlu, Y. (2020). Depo çalışanlarının bilişim sistemlerine yaklaşımları üzerine bir araştırma. Manas Sosyal Arastirmalar Dergisi, 9(3), 1762-1772.

Geliş Tarihi / Received Date: 24.03.2019

Kabul Tarihi / Accepted Date: 26.04.2020

\footnotetext{
${ }^{1}$ Kübra Sargın’nın “Etkin Depo Yönetimi ve Depo Planlamasında Bilişim Sistemleri Uygulaması” başlıklı Yüksek Lisans Tezinden üretilmiștir.

2 Aksigorta, sarginkubra@gmail.com - ORCID: 0000-0001-6342-7499

${ }^{3}$ Doç. Dr. - Yaşar Üniversitesi İşletme Fakültesi, yucel.ozturkoglu@yasar.edu.tr - ORCID: 0000-0002-9569-8178
} 


\section{Giriş}

Depolama faaliyetleri, hammaddenin temin edilip üretim süreçlerine dâhil edilmesinden, üretim süreçlerinden çıktı olarak ortaya konulan ürünlerin tüketicilere arz edilmesine kadar geçen sürede rol oynayan faaliyetlerdir. Bu faaliyetler esnasında çalışanların, kullanılan malzeme ve ekipmanlar ile eş zamanlı bütünleşmesi gerekmektedir (Bayraktar vd., 2011, s. 283). Depolama süreçlerinde yer alan tüm işlevlerin etkinliğine yönelik süreçlerin verimli olması noktasında anlık ve gerçek verilere ihtiyaç duyulmaktadır. $\mathrm{Bu}$ güvenilir veriler ise depolarda ancak bilgi teknolojilerinin kullanılması ile oluşabilmektedir. Özellikle küreselleşmenin etkisi ile yapısal olarak değişen piyasalarda depolamanın etkin ve verimli kullanılması, depolamanın maliyet kalemi olmaktan ziyade kârllı̆̆ga katkı sağlayan bir fonksiyon haline gelmesi noktasında bilişim sistemlerinin ve bilgi teknolojilerinin etkin olarak kullanılması şarttır.

Tedarik zinciri yönetim süreçlerinde ve lojistik faaliyetler kapsamında depolama faaliyetleri en önem arz eden faaliyetlerden biri olarak kabul edilmektedir. Depolar, hammadde, yarı mamul veya mamullerin üretiminden satısıına kadar uygun koşullar altında muhafaza edildiği, bekletildiği, konsolidasyon ve benzeri işlemlerin yapıldığ1 işletme bünyesindeki açık veya kapalı alanlardır (Öztürk, 2011, s. 15). Bu alanlarda üretilmiş olan mamul ya da ürünlerin saklanması faaliyeti de depolama olarak adlandırılmaktadır. Diğger bir tanımlamaya göre ise depolama, ürün açısından ürünün depodan çıkmasına kadar elde tutulması ve transferin fiziksel olarak belgelendirilmesine kadar geçen süreye verilen isimdir (Acar ve Ateş, 2011, s. 20).

Depolama süreçleri temel olarak üç temel unsur kapsamında; ürün akışı, stoklama ve sevkiyat- ele alınmaktadır (Tunçel ve Tuna, 2012, s. 18). Bu unsurlardan kabul süreci, ürün / malın depoya fiziksel olarak intikal etmesi ile başlayan bir süreçtir. Diğer bir ifade ile depolama süreci, kabul süreci ile başlamaktadır. Kabul süreci, depoya intikal eden ürünün kontrol edilmesi, hangi depolama alanına sevk edileceği işlemlerini kapsayan süreçtir. Depolama sürecinin stoklama unsuru, depoya kabul edilme sürecinden sonra, saklanacakları depo alanına intikal etmeleri ve burada saklanmaları sürecini kapsamaktadır. Depolama sürecinin son unsuru olan sevkiyat unsuru ise; ürün ya da malların kullanım alanlarına intikal ettirilmek üzere depodan ayrılması ile ilişkilidir.

Depolama unsuru, lojistik faaliyetlerin ana unsurlarından bir tanesi olarak kabul edilmektedir ve etkin planlanmış depolama süreçlerinin lojistik sürecin genel etkinliğine direkt olarak etkisi olmaktadır (Özcan, 2008, s. 279). Depoların daha etkin ve verimli şekilde çalışabilmesi için tüm süreçlerde bilgi teknolojilerine ilişkin altyapıların var olması ve süreçlerin bilgi toplumuna yönelik olarak bilgi kaynakları ile entegre bir şekilde çalışması gerekmektedir. Bilgi teknolojileri kapsamında tedarik zinciri yönetim süreçlerine ilişskin gelişmeler incelendiğinde, tedarik zinciri süreçlerindeki en önemli değişimlerin; müşterilerin istek ve ihtiyaçlarının belirlenmesi, ürünlere ilişkin kalite kontrol süreçlerinin iyileştirilmesi, dış çevrede yaşanan gelişmelerin analizi konularında olduğu görülmektedir (Ozbekler ve Ozturkoglu, 2020, s. 1504). Bilgi sistemleri ile müşterilerin istek ve ihtiyaçlarının belirlenmesi arasındaki organik bağ, temel olarak, müşterilerden etkin ve doğru bilginin toplanması ve toplanan bilgilerin analiz edilerek tedarik yönetim süreçlerine girdi olarak katılması ile ilgilidir (Long, 1989, s. 84).

Literatür detaylı olarak incelendiğinde depo yeri seçimi, depo dizaynı, depo performans ölçümü ve depo süreçleri gibi konular oldukça fazla çalışıldığı ve hala çalışılmakta olduğu görülmektedir. Tablo 1'de son beş yıla ait depo ile ilgili konularda çalışılmış makalelerin yazar ve yıl bilgileri bulunmaktadır.

Tablo 1. Son Beş Yula Ait Depo ile İlgili Çalısmalar

\begin{tabular}{|c|c|}
\hline $\begin{array}{l}\text { Depo yeri } \\
\text { seçimi }\end{array}$ & $\begin{array}{l}\text { Aktepe ve Ersöz, (2014); Brahimi ve Khan, (2014); Karmaker ve Saha,( 2015); Durak ve Yıldız, (2015); } \\
\text { Dey vd. (2016); Özbek ve Erol, (2016); Raut vd. (2017); Ergün ve Tamer,(2017); Yavuz,(2018) }\end{array}$ \\
\hline Depo dizaynı & $\begin{array}{l}\text { Battini vd.(2014); Öztürkoğlu (2016); Uztürk ve Büyüközkan, (2016); De Koster vd. (2017;) Öztürkoğlu ve } \\
\text { Hoser, (2019); Mourtzis vd. (2019) }\end{array}$ \\
\hline $\begin{array}{l}\text { Depo } \\
\text { performans } \\
\text { ölçümü }\end{array}$ & $\begin{array}{l}\text { Staudt vd. (2015); Khan vd. (2016); Kusrini vd..( 2018); Indrawati vd. (2018), Faber vd. (2018); } \\
\text { Laosirihongthong vd. (2018) }\end{array}$ \\
\hline Depo süreçle & $\begin{array}{l}\text { Pawlewsk (2015); Lam vd. (2015); Öztürkoğlu (2015); Lu vd. (2016); Kłodawski vd. (2017); Khan ve Yu, } \\
\text { (2019) }\end{array}$ \\
\hline
\end{tabular}

Depo süreçlerinde bilişim sistemleri, güncel hayatta yaygın olarak kullanılmasına rağmen literatürde sadece birkaç tane çalışma bulunmaktadır. Maliappis ve Kremmydas (2016), özellikle tarım ürünleri için tasarlanan depolarda kullanılması önerilen bilişim teknolojilerinin firmaya sağladığı avantajlar üzerine 
yoğunlaşmışlardır. Škerlič vd. (2017) çalısmalarında araba endüstrisinde yer alan modern depolarda kullanılan bilişim teknolojilerinin özelliklerini sıralamışlardır. Kabakçı ve Ocak (2019) ise depo yönetiminde yazılım sistemlerinin öneminde bahsetmiştir.

Firmaların depo operasyonlarını hızlı, güvenilir ve verimli bir şekilde yönetebilmeleri için bilişim sistemlerini mutlaka kullanmaları gerekmektedir. Ancak, literatür detaylı olarak incelendiğinde bu konu hakkında çok az akademik çalışma yapılmıştır. Özellikle, depo çalışanlarının, depo bilişim sistemlerine karşı alg1 ve tutumlarını ele alan hiçbir çalışmaya rastlanmamıştır. Bundan dolayı, bu çalışmada bilişim sistemlerine ilişkin uygulama yeteneklerinin depolama süreçlerine olan katkısını incelerken depo çalışanları üzerinde yoğunlaşarak onların bu konuda ki alg1 ve tutumlarının incelenmesi amaçlanmıştır. Elde edilen sonuçlar ile boşluk doldurulmaya çalısılarak, literatüre katkı sağlaması beklenmektedir.

Çalışma dört bölümden oluşmaktadır. Bundan sonra ki bölümde, depo yönetimde kullanılan bilişim sistemleri hakkında bilgi verilmektedir. Diğer bölüm de ise çalışmada kullanılan yöntem ve elde edilen sonuçlar yer almaktadır. Son bölümde ise elde edilen sonuçların yorumlanması bulunmaktadır.

\section{Depo Yönetimi}

\section{Depo Yönetiminde Bilişim Sistemleri}

Yönetim bilişim sistemleri, işletme faaliyetlerinin planlanması, kontrolü ve gelecekle ilgili tahminlerin yapılmasına imkan veren özet raporların hazırlanmasını ve sunulmasını sağlayan ve yönetim düzeyindeki planlama, kontrol ve karar verme fonksiyonlarını destekleyen bir sistemdir (Tekin vd., 2000, s. 16). Depolar ise lojistiğin katma değer üreten önemli fonksiyonlarından biridir. Depo hareketinin bittiği nokta, hızı sıfır olan bir nakliye şeklinde değerlendirilmektedir (Yıldıztekin, 2004, s.5). Bu sebeple, etkin bir depolama yönetim sistemi ile birlikte; stokların iyi yönetilmesi, envanter yönetiminin profesyonelleşmesi, kârlllığa olumlu katk1 sağlanması ve performans yönetiminin etkinleşmesi mümkündür (Hopbaoğlu, 2009, s. 20). Bu gereklilik ile ortaya çıkan depo yönetim sistemi kavramı, depoların etkin yönetilmesine yönelik planlamaların yapılması, depo ve depolamaya profesyonel olarak yaklaşılması, sistematik süreçlerin kurulması ve süreçlerin bilgi iletişim teknolojileri ile entegre edilerek etkinliğinin arttırılması konuları ile doğrudan ilişkilidir.

Depo yönetim sistemleri birçok farklı maliyet kalemini ve riskleri kapsamasına rağmen özellikle bilgi paylaşımının maliyeti ve depo yönetim sistemlerine yatırım yapmanın getirisini belirme belirsizliği riski soruları tam olarak cevaplanamamış iki önemli unsurdur (Dalgakıran ve Öztürkoğlu, 2017, s.149). Depo da yürütülen operasyonlarda gerekli, doğru ve anlık bilgi bulunabilirliği ancak farklı teknolojilerin kullanılması ile mümkün olabilir (Shi vd. 2016, s.190). Bu gibi sorunları bertaraf edebilmek için firmalar depo yönetim sistemlerine her geçen gün daha fazla yatırım yapmaları gerektiğini farkına varmaktadırlar.

Globalleşme sonucu, özellikle üretim ve depo faaliyetlerinin farklı ülke ve kıtalarda gerçekleştiği şirketler açısından entegrasyon büyük önem arz etmektedir. En hızlı, anlık ve güvenilir uyum için depo yönetiminde bilişim sistemleri profesyonel bir yaklaşım sergilemeketedir (Lee vd. 2018). Yeni dijital çağ ile birlikte endüstri 4.0 kavramının yaygınlaşması, özellikle teknolojik sistemlerinin ihtiyacını daha da açığa çıkarmıştır (Çakılcı ve Öztürkoğlu, 2020, s. 490). Etkin, verimli ve az maliyetli depo iş süreçleri için en uygun depo yönetim sistemleri teknolojilerini kullanmak gerekmektedir.

Depo yönetim sistemlerinin temel olarak depo yönetim sistemleri, barkod ve radyo frekans teknolojisi olarak üç ana başlıkta incelenmektedir.

\section{Depo Yönetim Sistemleri}

Depolama operasyonlarına genellikle depo yönetim sistemi yardımc1 olur. Depo yönetim sistemlerine yönelik geliştirilen yazılımların, depolama işlevlerine yönelik gerekli olan tüm bilgilerin standart halinde sisteme girilmesine olanak sağlayacak şekilde geliştirilmesi, kullanıcıdan kaynaklanan hataların minimize edilmesine yönelik çapraz doğrulama kurallarının tanımlanması ve depolama işlevlerine ilişkin oluşturulacak veri setinin minimum hata ile oluşturulmasına olanak sağlayacak şekilde geliştirilmesi gerekmektedir. Ayrıca, depolama yönetim sistemlerine ilişkin yazılımların, örgütün mevcut örgütsel süreçlerine (envanter raporları, stok raporları gibi) veri sağlayacak şekilde dizayn edilmesi önemli bir gerekliliktir (Sahuri and Utomo, 2016, p.18). Depo yönetim sistemleri tarafindan ortaya çıkartılan raporlar, sadece bilgilendirme işlevi ile sınırlı raporlar değillerdir. Bu raporlar bir anlamda, mevcut stok durumunu ortaya koymakta, müşteri ve satın alma siparişlerinin zaman içerisindeki seyrini göstermek sureti ile depolama ile ilişkin süreçlerde varsa sorunlu bölgelerin ortaya çıkartılmasını sağlamaktadır. 
Dolayısıyla, depo yönetim sistemleri kapsamında yer alan yazılımların raporlama ihtiyacına yönelik olarak da geliştirilmesi önemlidir (Hwa Chung and Snyder, 2000, p. 28). Depo yönetim sistemlerinin etkin olarak kullanıldığ1 bir örgütte var olan yazılım yardımı ile depolarda var olan stokların lokasyonlarına göre envanteri, stokların son kullanma tarihine göre listesi, müşteri siparişlerine ilişkin detay bilgileri, açık ve kapalı satın alma siparişleri raporlanabilmelidir. Bu kurumsal kaynak planlama (ERP) modülü, bir depodaki işlemleri denetleyerek mal ve bilgi akışını ve ayrıca personel görevlerini kontrol eder (Çalışkan vd. 2016, s.52). Bu sayede üreticiler ile müssteriler arasında performans izleme ve değerlendirme konusunda oldukça kolaylık sağlanabilmektedir (Ozturkoglu ve Esendemir, 2014, s. 364)

Bir tedarik zincirinin farklı seviyelerinde depo yönetim sistemlerinin getirilmesi, işletmelerin tedarik, üretim, depolama ve dağıtım faaliyetlerinde bile yararlanabilecekleri bilgi altyapılarının oluşturulmasını kolaylaştırır (Comuzzi ve Parhizkar, 2017, s. 2242). Her sistemin olduğu gibi depo yönetim sistemlerinin de etkin ve verimli olarak sürdürülebilmesi, bu sistemlerin örgüt amaç ve hedeflerine yönelik olarak beklenen katma değeri sağlaması noktasında örgüt ile uyumlu ve talepleri karşılayacak şekilde geliştirilmiş ve gerekirse örgüt özelinde entegrasyona tabi tutulmuş yazılımlar ile desteklenmesi şarttır. Diğer bir ifade ile yazllım depo yönetim sistemlerinin çekirdeğidir ve depolamaya ilişkin tüm işlevlerin yönlendirilmesi noktasında kritik faktör depo yönetim sisteminin yazılım bileşenidir (Atieh vd., 2016, s. 571).

Depo yönetim sistemlerinin yazılım bileşeni kapsamında yer alması gereken birtakım önemli özellikler, değerler, şartlar bulunmaktadır. Tüm bunlar, etkin bir yazılımın geliştirilmesi ve uygulanmasının sürdürülebilir k1lınması noktasında önem arz etmektedir. Depo yönetim sistemine ilişkin yazılımın öncelikle bir depo veri setine ihtiyaç duyduğu bilinmektedir. Her yazılım gibi, depo yönetim sistemlerine ilişkin yazılımlarda kodlanan veriler kapsamında yönetsel süreçlere destek verebilmektedir.

\section{Barkod}

Depo yönetim sistemlerinin bir diğer önemli bileşeni barkod teknolojisi olarak kabul edilmektedir. Lojistik ve depo yönetimine barkod teknolojisi uygulamak, depo süreçleri için kaçınılmaz bir eğilim haline gelmiştir. Barkod ilk olarak 1970'li yılların sonunda kullanılmaya başlanmasına rağmen hala çoğu depo yönetim sistemlerin de en yaygın olarak kullanılan teknolojidir (De Koster vd. 2017, s. 6328). Barkod en temel anlamda, verilerin çizgi ve boşluklardan oluşan semboller yardımı ile kodlanması ve bu kodların optik okuyucular yardımı ile bilgisayar sistemlerine aktarılması yani seri halindeki bir takım karakterlerin kodlanmasıdır (Sanal ve Öztürkoğlu, 2017, s. 176). Barkod sistemlerinde siyah ve beyaz çizgilerin temsil ettiğgi şifreler, bu şifreleri okuma yeteneği olan yazılımlar sayesinde bilgi sistemlerinde örgütler tarafindan belirlenmiş karakterlere dönüşür. Barkodlarda yer alan bilgiler, çok farklı okuyucular yardımı ile bilgi sistemlerine aktarılır ve bilgi sistemlerinde kullanıcılar tarafindan anlaşılabilecek dilde veri setlerine dönüştürülür.

Depolar da barkod kullanımının en temel faydası, çok büyük montajlı ürün, malzeme işlenen sistemlerde kontrolü sağlamasıdır (Eski vd., 2013, s. 37). Tedarik zinciri yönetiminde ve depolama sistemlerinde de barkod teknolojisi bu nedenle son derece önemlidir. Barkod teknolojisi yardımı ile depolama işlevlerinin etkin bir şekilde yönetilmesi mümkün olur. Depo içinde ürünlerin yerlerinin tespiti, stoklanan ürünlerin miktarları, seri numaraları ve ürüne ait özelliklerin doğru şekilde kontrol altında tutulması barkod sistemi ile gerçekleştirilir (Onar, 2004, s. 46). Ayrıca, envanterde yer alan malzemelerin düzenli ve standart bir şekilde sisteme aktarllmasına, sisteme aktarılan malzemelere ilişkin yapılan satışlarda doğru malzemenin stoktan çıkartılmasına, sevk edilen malzemelerin kontrolüne ve dolayısıyla da fiziki sayım ve envanter sistemindeki miktarlar arasında oluşacak fiyat/ miktar farklılıklarını önüne geçilmesine fayda sağlar.

\section{Radyo Frekansı Teknolojileri}

Radyo frekansı teknolojileri depolama sistemleri kapsamında ele alınan bir diğer bileşendir. Bu teknoloji sayesinde, barkodun aksine birden çok kullanım ile hem bilgi girilmesine hem de bilgive ulaşım mümkündür (Lee vd., 2011, p. 5432). Radyo frekans1 teknolojileri, depo yönetim sistemlerinin beyni olarak kabul edilen depo yönetim sistemi yazılımlarına, depolama süreçlerinde gerçekleştirilen eylemlerin direkt olarak ve hızlı bir şekilde aktarılmasına yardımcı olan sistemler olarak tanımlanmaktadır (Saygılı vd, 2017, s. 62). 
Radyo frekansı teknolojileri, entegre bir devre çipi ve RFID okuyucusundan iletilen radyo dalgalarına yanıt verme yeteneğine sahip bir anten içeren küçük bir etiket kullanır. Bilgi gönderebilir, işleyebilir ve saklayabilir. Barkod teknolojisine ek olarak, RFID fiziksel temas veya özel bir ihtiyaç duymayan bir tanımlama aracıdır. Ayrıca, radyo frekansı teknolojileri, eş zamanlı olarak okuma ve yazma özelliğine sahiptirler (Üstündağ, 2005, s. 34). Okuma aşaması çok hızlı ve tamamen otomatik. Bu sayede, içinde ki bilgiler güncellenerek birden fazla kullanılabilme olanağ1 sağlayarak maliyet açısından da barkod ile kıyaslandığında daha avantajlı bir durum elde edilir.

Radyo frekansı teknolojisi yardımı ile depolama sistemlerinde gerçekleştirilen eylemlerin eş zamanlı olarak tabir edilebilecek bir sürede, depolama sistem yazılımlarına aktarılması mümkün olmaktadır. $\mathrm{Bu}$ sayede, yazılım sistemlerinde depolama süreçlerinde gerçekleşen eylemlerin sonuçları eş zamanlı olarak raporlanabilmektedir. Dolayısıyla, depo ve depolama süreçlerinin işletmesi için rekabet avantajı olarak katkı sağlaması hedefinde olan tüm işletmelerin etkin depo yönetim sistemlerini kullanması şarttır.

Bahsedilen avantajlanın yanında, çeşitli teknik ve ekonomik engeller nedeniyle RFID teknolojilerinin gerçek uygulamaları hala sınırlıdır. Metal ve sıvı ortamlar, RFID teknolojilerinin okuma performanslarını bozabilir (Lee vd. 2018, s. 2754). Uluslararası standartların eksikliği bir başka ve en önemli dezavantajlarından biridir.

Doğru yere, doğru kapasite ile kurulan ve etkin bir şekilde bilgi teknolojilerinin de yardımı ile yönetilen depolama fonksiyonu, lojistik süreçler kapsamında şirketlere olumlu girdiler sağlayacak ve şirketlerin rekabet avantajı kazanarak, sürdürülebilirliklerini korumaları noktasında fayda sağlayacaktır.

\section{Uygulama}

Yürütülen bu araştırmada, bilişim sistemlerine ilişkin uygulama yeteneklerinin örgütlerin depolama sistemlerine olan katkısının incelenmesi amaçlanmıştır. Bu amaç kapsamında, etkin depo yönetim sistemine sahip olduğu belirlenen ve bilişim sistemleriyle depolama sistemleri arasındaki entegrasyonu sağlamış olan; öncelikle sanayi ve üretim sektörlerinde faaliyet gösteren örgütlerin sadece depo alanında ancak farklı görev tanımları olan çalışanlarına; depolama ve bilişim sistemleri konulu bir anket uygulanmış ve anket kapsamında bilişim sistemlerinin depolama ve depo yönetim sistemlerindeki yerinin ve öneminin ölçülmesi hedeflenmiştir.

Geliştirilen anket iki bölümden oluşmaktadır. İlk bölüm, anketi cevaplayanların demografik bilgilerini içeren; yaş, eğitim, çalışma deneyimi ve çalışılan bölüm bilgisinden oluşmaktadır. Anketin ikinci kısmı ise toplam 22 ifadeden oluşmaktadır ve her bir ifade için 5li likert ölçeği kullanılmıştır. Uygulanan anket kapsamında 156 kişi tarafindan elde edilen veriler, SPSS 22.0 paket programı yardımı ile istatistiksel olarak analiz edilmiştir.

Araştırma kapsamında kullanılan yirmi iki sorudan oluşan ölçeğe ilişkin güvenilirlik analizi yapılmış ve ifadelerin bütünü için Cronbach Alpha katsayısı hesaplanmıştır. Araştırma ölçeğinde yer alan toplam yirmi iki ifadenin Cronbach Alpha katsayısı 0,820 olarak hesaplanmıştır ve ölçek güvenilir bulunmuştur.

Anketin ilk kısmında yer alan demografik bilgiler şu şekilde sıralanmaktadır; katılımcıların 25 tanesi (\% 16) 21-30 yaş aralığında, 116 tanesi (\% 74,3) 31-40 yaş aralığında, 12 tanesi (\% 7,7) 41-50 yaş aralı̆̆ında ve 3 tanesi (\% 2) 50 yaş üzerindedir. Araştırmaya katılan katılımcılardan hiçbirisi 20 yaşından küçük değildir. Katıllımciların 1 tanesi (\% 1) lise mezunu, 4 tanesi (\% 2,6) ön lisans mezunu, 140 tanesi (\% 90) lisans mezunu ve 11 tanesi $(\%$, 6,4) yüksek lisans ya da doktora mezunudur. Katılımciların 2 tanesi $(\% 1,3)$ 1 yıldan az çalışma deneyimine sahiptir. 1-5 yıl arası çalışma deneyimi olan katılımcı sayısı 24 (\% 15,3), 6-10 yıl arası çalışma deneyimi olan katılımcı sayısı 115 (\% 73,7), 10-15 yıl arası çalışma deneyimi olan katılımcı sayıs $8(\% 5,1)$ ve 15 yıldan fazla çalışma deneyimi olan katılımcı sayısı 7 (\%4,6)'tir. Katılımcıların hepsi depoda görevli olup ancak deponun farklı alanlarında çalışmaktadırlar. 156 katılımcıdan; 119 tanesi $(\% 76,2)$ depo operasyonlarında çalışmaktadır. Depo bilgi işlem departmanı çalışanların sayısı $12(\% 7,7)$, depo sorumlusu sayıs $25(\% 16)$ olarak belirlenmiştir.

Bu çalışma kapsamında araştırmanın amacına yönelik olarak kurulan hipotezler aşağıdaki gibidir;

$\mathrm{H}_{1,0}=$ Depo çalışanlarının bilişim sistemlerine yönelik yaklaşımlarında, çalıştıkları pozisyonun etkisi vardır.

$\mathrm{H}_{1,1}=$ Depo çalışanlarının bilişim sistemlerine yönelik yaklaşımlarında, çalıştıkları pozisyonun etkisi yoktur.

$\mathrm{H}_{2,0}=$ Depo çalışanlarının bilişim sistemlerine yönelik yaklaşımlarında, çalışanların eğitim durumlarının etkisi vardır. 
$\mathrm{H}_{2,1}=$ Depo çalışanlarının bilişim sistemlerine yönelik yaklaşımlarında, çalışanların eğitim durumlarının etkisi yoktur.

$\mathrm{H}_{3,0}=$ Bilişim sistemlerinin, depo operasyonlarının basitleşmesinde ve standartlaşmasında katkısı vardır.

$\mathrm{H}_{3,1}=$ Bilişim sistemlerinin, depo operasyonlarının basitleşmesinde ve standartlaşmasında katkısı yoktur.

$\mathrm{H}_{4,0}=$ Bilişim sistemlerinin, depo operasyonlarına etkinliği ve verimliliği üzerinde katkısı vardır.

$\mathrm{H}_{4,1}=$ Bilişim sistemlerinin, depo operasyonlarına etkinliği ve verimliliği üzerinde katkısı yoktur.

Araştırma kapsamında kurulan hipotezlerin test edilmesine yönelik olarak ilk sırada; bilişim sistemlerine yönelik yaklaşımların, çalışılan pozisyon etkisi olup olmadığı incelenmiştir.

Araştırma, katılımcılarının çalıştıkları pozisyon ile bilişim sistemlerine yönelik yaklaşım üzerinde etkisi olup olmadığının incelenmesi kapsamında tek yönlü ANOVA testi yapılmıştır. Tek yönlü varyans analizi veya diğer ismi ile ANOVA testi, normal dağılımlı bir veri setinde, üç veya daha fazla bağımsız ortalama arasındaki farkın anlamlı olup olmadığını test etmek için kullanılır. ANOVA tek başına üç veya daha fazla grubun aritmetik ortalamalarını kümülatif olarak karşılaştırır; bu karşılaştırmalardan en az birisi anlamlı olduğunda ANOVA sonucu da anlamlı bulunur. Yapılan tek yönlü ANOVA testine ilişkin elde edilen tanımlayıc istatistik bulguları Tablo 2'de yer almaktadır.

Tablo 2. Depo İçi Çalşsılan Požisyon ile Bilişim Sistemleri Algısı

\begin{tabular}{lll}
\hline Departman İsimleri & Frekans & Ortalama \\
\hline Depo Operasyon Sorumlusu & 119 & 3,73 \\
Depo Bilgi İşlem Sorumlusu & 12 & 3,57 \\
Depo Sorumlusu & 25 & 3,21 \\
\hline
\end{tabular}

Katılımcıların depo için çalıștıkları pozisyon farklılıkların bilișim sistemleri yaklașımlarına ilișkin ortalama puanları üzerinde önemli bir değişme sahip olmadığı görülmektedir. Farklılık oluşmamasını tesadüfü bir dalgalanmadan kaynaklı olup olmadığına yönelik uygulanan tek yönlü ANOVA testinin sonuçları aşağıda yer almaktadır.

Tablo 3. Depo içi Calışılan Pozisyon ile Bilişim Sistemlerine Yaklașımı

\begin{tabular}{lrrrrr}
\hline & $\begin{array}{c}\text { Kareler } \\
\text { Toplami }\end{array}$ & df & $\begin{array}{c}\text { Ortalama } \\
\text { Kare }\end{array}$ & F & Anlamlılık \\
\hline Gruplar aras1 & 1,087 & 7 & 0,155 & 1,564 &, 169 \\
Grup İçi & 4,765 & 148 &, 099 & & \\
Toplam & 5,852 & 155 & & & \\
\hline
\end{tabular}

ANOVA tablosunun anlamll1ı sütunundaki (sig / p) değerin 0,000'dan büyük olduğu görülmektedir. Söz konusu değer, 0,000 'dan büyük olduğu için $\mathrm{p}=0,169>0,000$; kişinin depo içi çalıştı̆̆ pozisyon ile bilişim sistemlerine yaklaşımı arasında bir ilişki bulunmadığını 0,05 anlamlılık düzeyi ve \% 95 güven aralığında söylemek mümkündür. Dolayısıyla, kurulan hipotezlerden; " $\mathrm{H}_{1,0}=$ Depo çalışanlarının bilişim sistemlerine yönelik yaklaşımlarında, çalışıkları pozisyonun etkisi vardır" hipotezi ret edilir; " $\mathrm{H}_{1,1}=$ Depo çalışanlarının bilişim sistemlerine yönelik yaklaşımlarında, çalıştıkları pozisyonun etkisi yoktur" hipotezi kabul edilir.

Araştırma kapsamında kurulan hipotezlerin test edilmesine yönelik olarak bilişim sistemlerine yönelik yaklașımın demografik özelliklerden "eğitim durumunun" etkisi olup olmadığı incelenmiştir. Araştırma katılımcılarının eğitim durumlarının bilişim sistemlerine yönelik yaklaşım üzerinde etkisi olup olmadığının incelenmesi kapsamında tek yönlü ANOVA testi yapılmıştır. Yapılan tek yönlü ANOVA testine ilişkin elde edilen tanımlayıcı istatistik bulguları aşağıdaki gibidir;

Tablo 4. Eğitim Durumu ile Bilişim Sistemlerine Yaklaşım

\begin{tabular}{lll}
\hline Eğitim Durumu & Frekans & Ortalama \\
\hline Lise Mezunu & 1 & 3,9091 \\
Ön Lisans Mezunu & 4 & 3,3864 \\
Lisans Mezunu & 140 & 3,8125 \\
Yüksek Lisans / Doktora Mezunu & 11 & 3,8140 \\
\hline
\end{tabular}


Katılımcıların eğitim durumlarındaki değişimlerin bilişim sistemlerine yaklaşımına ilişkin ortalama puanları üzerinde önemli bir değişme sahip olmadığı görülmektedir. Farklılık oluşmamasını tesadüfü bir dalgalanmadan kaynaklı olup olmadığına yönelik uygulanan tek yönlü ANOVA testinin sonuçları aşağıda yer almaktadir.

Tablo 5. Eğitim Durumuna ile Bilişim Sistemlerine Yaklașım

\begin{tabular}{|c|c|c|c|c|c|}
\hline & $\begin{array}{c}\text { Kareler } \\
\text { Toplamı }\end{array}$ & df & $\begin{array}{c}\text { Ortalama } \\
\text { Kare }\end{array}$ & $\bar{F}$ & Anlamlilik \\
\hline Gruplararas1 & ,691 & 3 & 230 & 2,319 & ,086 \\
\hline Grup İçi & 5,162 & 152 & ,099 & & \\
\hline Toplam & 5,852 & 155 & & & \\
\hline
\end{tabular}

ANOVA tablosunun anlamlllk sütunundaki (sig / p) değerin 0,000'dan büyük olduğu görülmektedir. Söz konusu değer, 0,000 'dan büyük olduğu için $\mathrm{p}=0,086>0,000$; eğitim düzeyi ve bilişism sistemleri yaklaşımı arasında bir ilişki bulunmadığını 0,05 anlamlılık düzeyi ve \% 95 güven aralığında söylemek mümkündür. Dolayısıyla, araştırmanın eğitim düzeyi ve bilişim sistemleri algısına yönelik olarak kurulan iki hipotezinden; " $\mathrm{H}_{2,0}=$ Depo çalışanlarının bilişim sistemlerine yönelik yaklaşımlarında, çalışanların eğitim durumlarının etkisi vardır" hipotezi ret edilir; " $\mathrm{H}_{2,1}=$ Depo çalışanlarının bilişim sistemlerine yönelik yaklaşımlarında, çalışanların eğitim durumlarının etkisi yoktur" hipotezi kabul edilir.

Araştırma kapsamında kurulan diğer bir hipotez grubu ise bilişim sistemlerinin, depo operasyonlarını basitleştirilmesine yönelik yaklaşım ile ilişkindir. Bu hipotezin test edilmesine yönelik olarak yapılan tek yönlü t-testi sonuçları aşağıdaki gibidir;

Tablo 6. Bilişim Sistemleri - Depo Operasyonlarmm Basitleștirilmesi

\begin{tabular}{ccccc}
\hline Değişken & $\mathbf{t}$ & df & Anlamllık & Ortalama Farkları \\
\hline Depo Sistemlerinin Basitleştirilmesi & 46,100 & 155 & 0,000 & 3,98214 \\
\hline
\end{tabular}

Yukarıda yer alan tablo kapsamında, önem değerinin $p=0,000$ olarak oluştuğu ve 0,05 anlamllık düzeyinde istatistiksel olarak anlamlı olduğu görülmektedir. Bu değer kapsamında bilişim sistemlerinin, depo operasyonlarının basitleştirilmesi üzerinde etkisi olduğunu söylemek mümkündür. Dolayısıyla, araştırmanın bilişim sistemleri ve depo sistemlerinin basitleştirilmesi algısına yönelik olarak kurulan iki hipotezinden; " $\mathrm{H}_{3,1}=$ Bilişim sistemlerinin, depo operasyonlarının basitleşmesinde ve standartlaşmasında katkıs1 yoktur" hipotezi ret edilir; " $\mathrm{H}_{3,0}=$ Bilişim sistemlerinin, depo operasyonlarının basitleşmesinde ve standartlaşmasında katkısı vardır" hipotezi kabul edilir.

Araştırma kapsamında kurulan son hipotez grubu ise bilişim sistemleri, depo operasyonlarının etkinliğine ve verimliliğine yöneliktir. Bu hipotezin test edilmesine yönelik olarak yapılan tek yönlü $\mathrm{t}$-testi sonuçları aşağıdaki gibidir;

Tablo 7. Bilişim Sistemleri-Depo Etkinliği ve Verimliliği

\begin{tabular}{lcccc}
\hline \multicolumn{1}{c}{ Değişken } & t & df & Anlamlılık & Ortalama Farkları \\
\hline $\begin{array}{l}\text { Depo Operasyonlarına Etkinliği\& } \\
\text { Verimliliği }\end{array}$ & 49,284 & 155 & 0,000 & 3,96429 \\
\hline
\end{tabular}

Yukarıda yer alan tablo kapsamında anlamllık değerinin $p=0,000$ olarak oluştuğu ve 0,05 anlamlılık düzeyinde istatistiksel olarak anlamlı olduğu görülmektedir. Bu değer kapsamında bilişim sistemlerinin depo operasyonlarına etkinliği ve verimliliği üzerinde etkisi olduğunu söylemek mümkündür. Dolayısıyla, araştırmanın bilişim sistemleri ve depo sistemlerinin etkinliği ve verimliliğine yönelik olarak kurulan iki hipotezinden; " $\mathrm{H}_{4,1}=$ Bilişim sistemlerinin depo operasyonlarına etkinliği ve verimliliği üzerinde katkıs1 yoktur" hipotezi ret edilir; " $\mathrm{H}_{4,0}=$ Bilişim Sistemlerinin depo operasyonlarına etkinliği ve verimliliği üzerinde katkısı vardır” hipotezi kabul edilir.

Yürütülen istatistiksel analizler kapsamında araştırma hipotezlerinin hangilerinin kabul hangilerinin ret edildiğine ilişkin özet tablo aşağıdaki gibidir; 
Tablo 8. Kabul Edilen Hipotęler

\section{Hipotez}

$\mathrm{H}_{1,1}=$ Depo çalışanlarının bilişim sistemlerine yönelik yaklaşımlarında, çalıştıkları pozisyonun etkisi yoktur.

$\mathrm{H}_{2,1}=$ Depo çalıșanlarının bilișim sistemlerine yönelik yaklaşımlarında, eğitim durumlarının etkisi yoktur.

$\mathrm{H}_{3,0}=$ Bilişim sistemlerinin, depo operasyonlarının basitleşmesinde ve standartlaşmasında katkısı vardır.

$\mathrm{H}_{4,0}=$ Bilişim Sistemlerinin depo operasyonlarına etkinliği ve verimliliği üzerinde katkısı vardır.

\section{Tartışma, Sonuç ve Öneriler}

Örgütlerin bünyesinde var olan tüm sistemlerin, esnek, müșteri istek ve ihtiyaçlarını tatmin edecek düzeyde ve mutlak surette bilgi teknolojileri ile entegre bir şekilde kurulması gerekmektedir. Dolayısıyla, örgütlerin tedarik zinciri yönetimi sürecinde kritik bir faktör olarak kabul edilen depolama süreçlerinin de yönetim sistemleri kapsamında ve bilişim sistemlerinin yardımı ile yönetilmesi ve bu sistemlerin etkin ve verimli sonuçlar oluşturabilmesi için kontrol edilmesi şarttır.

Depo konusunda oldukça farzla çalışma yapılmasına rağmen, depo çalışanlarının, depo bilişim sistemlerine karşı yaklaşımlarını ele alan hiçbir çalışmaya rastlanılmamışır. Bundan dolayı, bu çalışmada bilişim sistemlerine ilişkin uygulama yeteneklerinin depolama süreçlerine olan katkısını incelerken depo çalışanları üzerinde yoğunlaşarak onların bu konuda ki yaklaşımlarının incelenmesi amaçlanmıştır. Elde edilen sonuçlar ile boşluk doldurulmaya çalış1larak, literatüre katkı sağlaması beklenmektedir.

Yürütülen bu çalışmada, oldukça karmaşık süreçler içeren ve geniş bir yönetsel perspektif ile yönetilmesi gereken depolama sistemleri ve bilişim teknolojileri / sistemleri arasındaki organik bağ incelenmiştir. Bu kapsamda, temel argüman bilişim sistemleri ile depo sistemleri arasında bağ olup olmadığının belirlenmesine yöneliktir. Geliştirilen anket kapsamında elde edilen verilerin analizi sonucunda, bilişim sistemlerinin depo yönetim sistemlerinin karmaşık düzeylerini basitleştirmede ve depo yönetim sistemlerinin standartlaşmasına katk1 sağlamada önemli bir değişken olduğu tespit ediliştir. Ayrıca, katılımcılarının yanıtlan kapsamında da bilişim sistemlerinin depo yönetim sistemlerinin etkinliğine ve verimliliğine katkısı olduğuna yönelik sonuçlar elde edilmiştir. Çalışma da ayrıca, bilişi̇m sistemlerine yönelik olarak örgüt çalışanlarının algıları da ölçülmeye çalışılmıştır. Anket kapsamında elde edilen bulgular doğrultusunda, bilişim sistemlerine ilişkin örgüt çalışanlarının algılanı çalışılan departmandan ya da çalışanın sahip olduğu eğitim düzeyinden etkilenmemektedir sonucuna ulaşılmışır.

Sonuç olarak, bilişim sistemleri, günümüz bilgi toplumlarında, örgütlerin faaliyetleri açısından son derece önemli olan sistemlerdir. Özellikle yeni dijital sanayi devriminin başlaması ile bilişim sistemleri ve teknolojileri hem üretim yapılan yerlerde hem de lojistik süreçlerin en önemli halkası olan depolarda artık lüks olmaktan çıkıp temel ihtiyaç haline gelmiştir. Bilişim sistemlerinin entegre edildiği örgüt süreçlerinin etkinliği ve verimliliği artmakta ve sistemlerde kullanıcılardan kaynaklı hatalar minimize edilmektedir. Bu kapsamda da dolaylı olarak; daha az hata yapan çalsşanların işe bağlılıkları artmakta ve işten ayrılma niyetleri azaltılmaktadır. Dolayısıyla, denilebilir ki bilişim sistemleri örgütlerin yaşam sürelerinin uzatılması ve rekabet avantajlarını kaybetmemesi noktasında kritik önem taşımaktadır.

\section{Etik Beyan}

"Depo Calışanlarmmn Bilişim Sistemlerine Yaklaşımlar Üzerine Bir Araştırma" başlıklı çalışmanın yazım sürecinde bilimsel, etik ve alıntı kurallarına uyulmuş; toplanan veriler üzerinde herhangi bir tahrifat yapılmamış ve bu çalışma herhangi başka bir akademik yayın ortamına değerlendirme için gönderilmemiştir.

\section{Kaynakça}

Acar, D. ve Ateş, A. B. (2011). Tedarik zincirinin temel faaliyetlerinde dış kaynak kullanımı: tekstil-konfeksiyon sektörü işletmelerinde bir araştırma. Mali Çözüm Dergisi, 17-46.

Aktepe, A. ve Ersöz, S. (2014). AHP-VIKOR ve MOORA yöntemlerinin depo yeri seçim probleminde uygulanmasi. Journal of Industrial Engineering (Turkish Chamber Of Mechanical Engineers), 25.

Atieh, A. M., Kaylani, H., Al-Abdallat, Y., Qaderi, A., Ghoul, L., Jaradat, L. ve Hdairis, I. (2016). Performance improvement of inventory management system processes by an automated warehouse management system. Procedia Cirp, 41, 568-572.

Battini, D., Persona, A. ve Sgarbossa, F. (2014). Innovative real-time system to integrate ergonomic evaluations into warehouse design and management. Computers \& Industrial Engineering, 77, 1-10. 
Bayraktar, D., Bolat, H. B., Fakı, B. M. ve Çelikkol, S. G. (2011). Depo süreçlerinde performans ölçümü ve değerlendirmesi için bir model önerisi. XI. Üretim Arastırmalar Semposyumu, 23-24 Haziran, 382-392, İstanbul.

Brahimi, N. ve Khan, S. A. (2014). Warehouse location with production, inventory, and distribution decisions: a case study in the lube oil industry. 4OR, 12(2), 175-197.

Chow, H. K., Choy, K. L., Lee, W. B. ve Lau, K. C. (2006). Design of a RFID case-based resource management system for warehouse operations. Expert Systems with Applications, 30(4), 561-576.

Comuzzi, M. ve Parhizkar, M. (2017). A methodology for enterprise systems post-implementation change management. Industrial Management \& Data Systems, 117(10), 2241-2262.

Çakılcı, C. ve Öztürkoğlu, Y. (2020). Analysis os sustainable e-logistics activities with analytic hierarchy process. Issletme Arasttrmalarn Dergisi, 12(1), 489-497

Çalişkan, A., Karacasulu, M. T. ve Öztürkoğlu, Y. (2016). Hizli moda markalarinda çevik ve esnek tedarik zinciri yönetimi. Celal Bayar University Journal of Social Sciences/Celal Bayar Üniversitesi Sosyal Bilimler Dergisi, 14(4), 49-73.

Dalgakiran, A. B. ve Öztürkoğlu, Y. (2017). Scale and relationship analysis for Turkish furniture sector. Business \& Management Studies: An International Journal, 5(1), 147-161.

De Koster, R. B., Johnson, A. L. ve Roy, D. (2017). Warehouse design and management. International Journal of Production Research, 55 (21), 6327-6330.

Dey, B., Bairagi, B., Sarkar, B. ve Sanyal, S. K. (2016). Warehouse location selection by fuzzy multi-criteria decision making methodologies based on subjective and objective criteria. International Journal of Management Science and Engineering Management, 11(4), 262-278.

Durak, I. ve Yıldız, M. S. (2015). P-Medyan tesis yeri seçim problemi: bir uygulama. Journal of Alanya Faculty of Business/Alanya Isletme Fakültesi Dergisi, 7(2).

Ergün, G. ve Eren, T. (2017). Lojistik dağıtım ağ problemlerinde analitik hiyerarşi prosesi yöntemi ve hedef programlama ile depo seçimi. Harran Üniversitesi Mühendislik Dergisi, 2(1), 1-13.

Eski, Ö., Araz, C., Delan, T. Ve Bayoğlu, L. (2013). Radyo frekans tanımlama sistemine dayalı hammadde depo yönetimi. Celal Bayar Üniversitesi Fen Bilimleri Dergisi, 9(2), 31-44.

Faber, N., De Koster, R. B. ve Smidts, A. (2018). Survival of the fittest: the impact of fit between warehouse management structure and warehouse context on warehouse performance. International Journal of Production Research, 56(1-2), 120-139.

Hopbaoğlu, F. (2009). Tedarik zincirinde ve lojistik süreçlerde depo tasarımı ve depo yönetimi: kozmetik sektöründe bir uygulama (Yayınlanmamış Yüksek Lisans Tezi), İTÜ Fen Bilimleri Enstitüsü, İstanbul.

Hwa Chung, S. ve Snyder, C. A. (2000). ERP adoption: a technological evolution approach. International Journal of Agile Management Systems, 2(1), 24-32.

Kabakçi, A.ve Ocak, N. (2019). Yaz̨llım sistemleri içerisinde depo yönetimi. Hiperlink Eğit. İlet. Yay. San. Tic. ve Ltd. Şti..

Kahya, S. Ö. ve Aydın, S. (2014). Tedarik zinciri yönetiminde bilgi sistemleri ve deri hazır giyim sektörüne bir yazılım önerisi. Tekstil ve Mühendis, 21 (96).

Karmaker, C. ve Saha, M. (2015). Optimization of warehouse location through fuzzy multi-criteria decision making methods. Decision Science Letters, 4(3), 315-334.

Khan, S. A., Dweiri, F. ve Chaabane, A. (2016, December). Fuzzy-AHP approach for warehouse performance measurement. In 2016 IEEE International Conference on Industrial Engineering and Engineering Management (IEEM) (pp. 871-875). IEEE.

Khan, S. A. R. ve Yu, Z. (2019). Warehouse Design and Management. In Strategic Supply Chain Management (pp. 139-154). Springer, Cham.

Kłodawski, M., Lewczuk, K., Jacyna-Gołda, I. ve Żak, J. (2017). Decision making strategies for warehouse operations. Archives of Transport, 41.

Kusrini, E., Novendri, F. ve Helia, V. N. (2018). Determining key performance indicators for warehouse performance measurement-a case study in construction materials warehouse. In MATEC Web of Conferences, 154, 01058). EDP Sciences.

Lam, H. Y., Choy, K. L., Ho, G. T. S., Cheng, S. W. Ve Lee, C. K. M. (2015). A knowledge-based logistics operations planning system for mitigating risk in warehouse order fulfillment. International Journal of Production Economics, 170, 763-779.

Laosirihongthong, T., Adebanjo, D., Samaranayake, P., Subramanian, N. ve Boon-itt, S. (2018). Prioritizing warehouse performance measures in contemporary supply chains. International Journal of Productivity and Performance Management, 67(9), 1703-1726.

Lee, C.K.M., Ho W., Ho, G.T.S. ve Lau, H.C.W. (2011). Design and development of logistics workflow systems for demand management with RFID. Expert Systems with Applications, 38, 5428-5437.

Lee, C. K. M., Lv, Y., Ng, K. K. H., Ho, W. ve Choy, K. L. (2018). Design and application of Internet of thingsbased warehouse management system for smart logistics. International Journal of Production Research, 56(8), 27532768.

Long L. (1989). Management information systems. New Jersey: Prentice Hall.

Lu, W., McFarlane, D., Giannikas, V. ve Zhang, Q. (2016). An algorithm for dynamic order-picking in warehouse operations. European Journal of Operational Research, 248(1), 107-122. 
Indrawati, S., Miranda, S. ve Pratama, A. B. (2018, August). Model of Warehouse Performance Measurement Based on Sustainable Warehouse Design. In 2018 4th International Conference on Science and Technology (ICST) (pp. 1-5). IEEE.

Mourtzis, D., Samothrakis, V., Zogopoulos, V. ve Vlachou, E. (2019). Warehouse Design and Operation using Augmented Reality technology: A Papermaking Industry Case Study. Procedia CIRP, 79, 574-579.

Onar, Ö.M. (2004). Hayatımızdaki Siyah Beyaz Çubuklar: Barkod. 3D Lojistik Dergisi, 3, 46-47.

Ozbekler, T. M. ve Ozturkoglu, Y. (2020). Analysing the importance of sustainability-oriented service quality in competition environment. Business Strategy and the Environment, 29(3), 1504-1516.

Ozturkoglu, Y. ve Esendemir, E. (2014). ERP Software selection using IFS and GRA methods. Journal of Emerging Trends in Computing and Information Sciences, 5(5), 363-370.

Özbek, A. ve Erol, E. (2016). COPRAS ve MOORA yöntemlerinin depo yeri seçim problemine uygulanmas1. Ekonomi İsletme Siyaset ve Uluslararasi İliskiler Dergisi, 2(1), 23-42.

Özcan, S. (2008). Küçük ve orta büyüklükteki işletmelerde lojistik yönetiminin önemi. Mustafa Kemal Üniversitesi Sosyal Bilimler Enstitüsü Dergisi, 5 (10), 275-300.

Öztürk, A. (2011). Etkin depo yönetimi ve lojistik depoların etkin depo stratejileri üzerine bir araştırma (Yayınlanmamış Yüksek Lisans Tezi), İstanbul Ticaret Üniversitesi Sosyal Bilimler Enstitüsü, İstanbul.

Öztürkoğlu, Ö. (2015, May). Investigating the robustness of aisles in a non-traditional unit-load warehouse design: Leverage. In 2015 IEEE Congress on Evolutionary Computation (CEC) (pp. 2230-2236). IEEE.

Öztürkoğlu, Ö. (2016, July). Effects of varying input and output points on new aisle designs in warehouses. In 2016 IEEE Congress on Evolutionary Computation (CEC) (pp. 3925-3932). IEEE.

Öztürkoğlu, Ö. ve Hoser, D. (2019). A discrete cross aisle design model for order-picking warehouses. European Journal of Operational Research, 275(2), 411-430.

Pawlewski, P. (2015, June). DES/ABS approach to simulate warehouse operations. In International Conference on Practical Applications of Agents and Multi-Agent Systems (pp. 115-125). Springer, Cham.

Raut, R. D., Narkhede, B. E., Gardas, B. B. ve Raut, V. (2017). Multi-criteria decision making approach: a sustainable warehouse location selection problem. International Journal of Management Concepts and Philosophy, 10(3), 260-281.

Sahuri, G. ve Utomo, F. A. P. (2016). Warehouse management system. Information System Application, 1(1), 16-23.

Sanal, A. ve Ozturkoglu, Y. (2017). Hizmet sektöründe QR kod kullanım alanlarına yönelik bir alan çalışması. Business and Management Studies: An International Journal, 5(4), 172-189.

Saygili, E. E., Ozturkoglu, Y. ve Kocakulah, M. (2017). End users' perceptions of critical success factors in ERP applications. International Journal of Enterprise Information Systems, 13(4), 58-75.

Shi, Y., Zhang, A., Arthanari, T., Liu, Y. ve Cheng, T.C. (2016). Third-party purchase: an empirical study of thirdparty logistics providers in China. International Journal of Production Economics, 171(2), 189-200.

Škerlič, S., Muha, R. ve Sokolovskij, E. (2017). Application of modern warehouse technology in the Slovenian automotive industry. Transport, 32(4), 415-425.

Staudt, F. H., Alpan, G., Di Mascolo, M. ve Rodriguez, C. M. T. (2015). Warehouse performance measurement: a literature review. International Journal of Production Research, 53(18), 5524-5544.

Tekin, M., Güleş, K.H. ve Burgess, T. (2000). Değissen dünyada teknoloji yönetimi. Konya: Damla Ofset.

Tunçel, G. ve Tuna, G. (2012). Depo yönetiminde sipariş toplama sistemleri: bir literatür araştırması. Dokuz. Eylül Üniversitesi Mühendislik. Fakültesi Mühendislik Bilimleri Dergisi, 14 (42), 15-31.

Üstündağ, A. (2005). RFID teknolojisi ile iş süreçlerinde paradigma değişikliği. Lojistik Dergisi, 5, 33-37.

Uztürk, D. ve Büyüközkan, G. (2016, December). A QFD approach for sustainable warehouse design. In XIV. International Logistics and Supply Chain Congress (pp. 257-265).

Yavuz, O. (2018). Depo yeri seçimi probleminde gri sistem teorisi ve VIKOR yönteminin karşılaştırmalı analizi. İstanbul Gelişim Üniversitesi Sosyal Bilimler Dergisi, 5(1), 169-191.

\section{EXTENDED ABSTRACT}

In supply chain management processes, warehouse is considered one of the most important activities. In order for the warehouses to operate more efficiently and efficiently, there should be infrastructures related to information technologies in all processes and the processes should work in an integrated way with information sources for the information society. With an efficient storage management, system; good management of inventory, professionalization of inventory management, positive contribution to profitability and performance management are possible. The warehouse management systems are examined under two main headings as barcode and radio frequency technology. In the most basic sense, the barcode is coded with the help of symbols consisting of lines and spaces, and these codes are transferred to computer systems with the help of optical readers. Radio frequency technologies are defined as systems that help the warehouse management system software, which is considered to be the brain of the warehouse management systems, directly and quickly transfer the actions carried out in the storage processes. There are some important features, values and conditions that should 
be included in the software component of warehouse management systems. All this is important in terms of making the development and implementation of effective software sustainable. It is known that the software for the warehouse management system first needs a warehouse data set. Like every software, it can support the managerial processes within the scope of the data encoded in the software for warehouse management systems.

When the developments regarding the supply chain management processes within the scope of information technologies are analyzed, the most important changes in the supply chain processes are; It is seen that the customers' requests and needs are determined, improvement of the quality control processes related to the products and analysis of the developments in the external environment. In this study, it is aimed to examine the contribution of application skills related to information systems to storage processes. The aim of this study is to examine the contribution of the additions to the storage systems of organizations. Within this scope, it has been determined that it has an efficient warehouse management system and has ensured the integration between information systems and storage systems; the employees of the organizations operating in the industry and production sectors. A questionnaire was developed to measure the importance and place of information systems in storage and warehouse management systems with the perception of employees. The developed questionnaire consists of two parts. The first section includes demographic information of respondents; age, education, working experience and departmental knowledge. The second part of the questionnaire consisted of 22 statements and 5-point Likert scale was used for each expression. The data obtained from the questionnaire were analyzed statistically with the help of SPSS 22.0 package program. The Cronbach Alpha coefficient of the twenty-two statements in the research scale was calculated as 0.820 and the scale was found to be reliable. In this study, four different hypotheses were established for the purpose of the study. Total 156 people, primarily in industry and production sectors, answered the questionnaire questions. One-way ANOVA and t-test were used for analysis.

As a result of the analysis of the data obtained, it is determined that information systems are an important variable in simplifying the complex levels of warehouse management systems and contributing to the standardization of warehouse management systems. In addition, the results showed that information systems contributed to the efficiency and efficiency of warehouse management systems. In the study, the perceptions of the employees of the information systems are tried to be measured. In the light of the findings obtained within the scope of the survey, the education department or the level of education of the employee does not affect the perceptions of the employees of the information systems related to the information systems.

To summarize, information systems are systems that are extremely important for the activities of organizations in today's information societies. The efficiency and efficiency of the organizational processes in which the information systems are integrated is increased and the errors caused by the users in the systems are minimized. In this context, indirectly; employees who make fewer mistakes increase their commitment to work and reduce their intention to quit. Therefore, it can be said that information systems are critical for prolonging the life span of organizations and not losing their competitive advantages. Therefore, it is imperative that all enterprises aiming to contribute as a competitive advantage for the operation of warehouse and storage processes should use efficient warehouse management systems. The storage function, which is established with the right capacity and with the help of information technologies effectively, will provide positive inputs to the companies within the scope of logistics processes and will benefit from the companies gaining competitive advantage and maintaining their sustainability. 